IJBE: Integrated Journal of Business and Economics

e-ISSN: 2549-3280

DOI: $10.33019 /$ /ijbe.v2i2.81

Date of Publication: 5 June 2018

Volume 2 Issue 2, pp. 220-232

\title{
Exploring Goal Commitment Predictors of Boundary Role Persons (BRP)
}

\author{
Nurus Sa'adah', Fathul Himam², Achmad Sobirin ${ }^{3}$

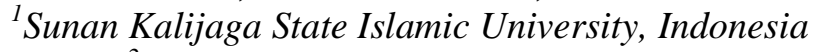 \\ ${ }^{2}$ Gadjah Mada University, Indonesia \\ ${ }^{3}$ Islamic University of Indonesia, Indonesia \\ Nurus.sa'adah@uin-suka.ac.id
}

\begin{abstract}
As the face of the organization, BRPs were the target of representations and influence attempts by external agents. In effect, the BRPs were both the influencer and the recipient of influence from insiders and outsiders. This basic characteristic led potentially to higher levels of role conflict and tension for the BRPs than other organization members. Because of high risk and challenges, BRPs had to have goal commitment to maintain their loyalty. This study aimed to explore goal commitment predictors of BRPs. Data collection involved 162 colleges promotion officers in Yogyakarta and it was analysed through Partial Least Square (PLS). The results indicated that R-square on the goal commitment was 0,398. The effect of conscientiousness on goal commitment was indicated by a correlation of 0,323 and $t=4,245$; the effect of communication climate on goal commitment was indicated by a correlation value of 0,206 and $t=2,545$; the effect of equity reward on goal commitment was indicated by a correlation value of 0,092 and $t=1,534$; the effect of opponent cooperation on goal commitment was indicated by $a$ correlation value of 0,203 and $t=2,915$. The conclusion was communication climate, opponent cooperation, and conscientiousness influenced goal commitment significantly, but equity reward did not influence goal commitment significantly.
\end{abstract}

Keywords: Goal commitment, Conscientiousness, Communication climate, Opponent cooperation, and Reward equity

\section{Introduction}

The organization is a system in which there are subsystems that have distinct divisions of work but in synergy towards a common goal. Development of an organization requires other parties outside the organization so that the organization needs to interact well with the environment outside. It proves that an organization has an open system (Berrien, 1976). Organizational openness to the outsiders in the nature of interactions includes input (procurement) and outputs (distribution of processing products both services, goods, and the results of decisions). Other terms are part of the search and distribution of products. This section is the edge or boundary of organizations, commonly referred to as "boundary" (Adams, 1976; Diamond, Alcorn, \& Stern, 2004; Perry \& Angle, 1979). 


\section{IJBE: Integrated Journal of Business and Economics}

e-ISSN: 2549-3280

Research on boundary appeared in various scientific journals with various meanings. In language, "boundary" means the boundary (Echols \& Shadily, 1987). As for the social studies, the experts defined "boundary" in various meanings. There are some experts interpret the boundary as the boundary between themselves with others and among themselves with the environment (Schredl, Bocklage, Engelhardt, \& Mingeback, 2008; Zaremba, 2005), normative constraints (Winslow \& Winslow, 2007), and the boundaries between organizations with environment outside the organization (Adams, 1976; Perry \& Angle, 1979). The boundary in this study is defined as a boundary organization.

An organizational boundary is interpreted as a line indicating its frontiers or boundaries identity when members of the organization met with members of other organizations. The meeting of two or more members of the different organizations is usually the case when certain interactions to represent the interests of their respective organizations in both the input and output processes. Input and output processes require transactions process effectively and efficiently so that the organization's activities run smoothly. Organizations usually appoint several individuals to represent the interests of the organization in dealing with outsiders. Individuals in this position are called the Boundary Role Persons (BRP). Individuals in this position include marketing, sales, advertising, representative, spokesman, bank teller, and teachers.

BRP term appeared in 1976 (Adams, 1976). Spekman in 1979 tried to reinforce the concept of BRP by examining the BRP of purchasing agent. Spekman (1979) examined the role of BRP in the internal organization. His research result shows that the social forces that contain a positive perception of fellow members of the organization towards BRP affect BRP performance when dealing with parties outside the organization. Perry and Angle (1979) developed a research on the influence of psychological closeness between constituents with BRP to the success of bargaining. Unfortunately, this kind of BRP studies unsustainable at the beginning of the arcing of this BRP term. Perry and Angle (1979) strengthen this argument by stating that in the early years of the emergence of its term, BRP has not attracted the attention of researchers.

Entering the 1990s, BRP studies began to bloom again because the experts realize that the problems of the individuals in the organization's boundaries need to be explored further so that the concept of BRP is considered appropriate to resolve. Most BRP studies focus on the problem of job stress (Cooper, Rout, and Faragher, 1989). This is due to the character of BRP at high-risk work, a lot of temptations and challenges, as well as facing unpredictable conditions. Facing this situation, the stability of loyalty should be owned by every BRP which is rarely accompanied by superiors (Adams, 1976). Loyalty to the organization begins with a commitment to work goals.

BRP who have a strong commitment will be able to perform jobs at any risks and barriers. Risks and obstacles faced will be transformed into positive energy in order to be more excited about achieving goals. It is very significant for the sustainability of an organization including universities. There are several positions in college BRP, such as procurement section, staffs who directly serve students, any section of international relations, public relations section, and a section that promotes the college. This study focuses on the promotion of higher education. Higher education promotion sections need to have a strong commitment towards goals so that they are willing to provide the best for the college. Yogyakarta is well-known as student city in 
Indonesia. Although it is still less than the number of colleges in other provinces in Indonesia, however when it is seen from the ratio of the number of area colleges, Yogyakarta has the highest ratio. It means that there is a strong rivalry between the universities and other universities. One of the competitions is competition in the market grab.

All campuses compete to win over prospective students with a variety of ways but referring to DuBrin (1996) that humans are the most important factor among other resources. Thus, it is appropriate if the human resources are considered in order to have a strong commitment to achieving campaign objectives set. Based on this problem, to obtain, manage, and maintain a reliable promotion forces then it necessary to explore empirically what the factors that can affect goal commitment of BRP are?

Based on the mapping of the results studies indicated that the goal commitment has the highest contribution to the success of BRP work than other variables. It is supported by empirical findings by Kamdar and Dyne (2007) which states that the goal commitment significantly influences the performance of the BRP. Commitment to the goal itself is influenced by internal factors, interactive, and external (Locke, Latham, \& Erez, 1988). The results of a meta-analysis of Klein, Alge, Wesson, and Hollenbeck (1999) showed that the sequence of the variables that contribute greatly to the BRP goal commitment is the social environment. The social environment in the study is BRP perception to superiors' support is embodied in the communication climate variables. Aside from the internal organization, BRP is also related to the social environment outside the organization which is realized in the cooperative partner variables in this study.

BRP internal factor which is used as goal commitment antecedent in this research is conscientiousness. It is supported by empirical evidence stating that conscientiousness significantly influences goal commitment (Jadhav, 2007). The external factor associated with goal commitment in this study is realized by reward equity variable. The selection of reward equity variable refers to the model of goal commitment by Locke et al. (1988) that goal commitment is influenced by factors such as internal, external, and interactive. In this consideration, the variables used as an antecedent of goal commitment in this research are conscientiousness, cooperative partners, communication climate, and pay equity.

BRP works more outside the organization, more in touch with the outside, be able to solve problems in the field, and be able to explain information about the internal desires, hopes, and needs to external and vice versa, and then the proponents of motivational factors are required. These motivational factors are the basis of the success of BRP's works. Therefore, this study focuses on finding out motivational predictors that influence BRP's goal commitment. By the findings of a predictor for the BRP's goal commitment, it is expected to be able to optimize the success of the college promotion. By this explanation, the problem formulation is whether there are influences of communication climate, cooperative partner, conscientiousness, and reward equity to BRP's goal commitment?

The purpose of this study is to find factors that can predict the BRP's goal commitment by involving variables of communications climate, cooperative partners, conscientiousness, and reward equity. With the findings, it is expected to bring the implications and recommendations of 
both theoretically and practically. In this regard, this study will be useful both theoretically and practically.

\section{Literature Reviews}

Theoretical benefit is the development of the BRP concept which connects the BRP's goal commitment to several variables that have been recently studied partially by previous researchers. This study also complements earlier research on the predictors of BRP's goal commitment that still need deepening and publication particularly comprehensive understanding of BRP promotion officer of Higher Education.

The practical benefit is the results of this study raised the organization's view, especially the academic community, to the role of BRP which is just as important as the role of other divisions in the organization so that the organization can assess BRP proportionally. These results can be used as a managerial reference to improve the quality of BRP's work and solve the psychological problems of BRP in higher education especially increasing of goal commitment. This study can also be used as a reference material of human resource management of higher education promotion. HR management which meant, among others, are the BRP's selection and development programs, from the views of such factors, individual, organizational, and interorganizational.

The novelty of this research lies in the study focused on the antecedents of BRP's goal commitment. Searching to the results of previous researches on the BRP journals and scientific articles indicate that most of the researchers have focused on BRP's job stress (Cooper, Rout, and Faragher, 1989 and Gilboa, Shirom, Fried, \& Cooper, 2008), with most the subject is the salespersons of products (Mehra \& Schenkel, 2005) while this study focused on the persons assigned to search for prospective students to the college system sustainability. In addition to differences in the research subjects' character of the BRP, character of the organization is also different to with previous BRP studies which are more focused on the BRP of business organization. There might be a difference between the characters of education organization with business organizations. Actually, Pruitt and Schwartz (1999) have conducted BRP research in education, but it is limited to the internal boundary of colleges and is still descriptive only examine whether the student affairs also includes BRP categories, instead of examining BRP's goal commitment. This study focuses on BRP's goal commitment that relates directly to external stakeholders, namely the promotion division of higher education.

Every organization absolutely has the direction towards achieving the goal of which are goals, programs, indicators of achievement, and achievement timing gradually. This goal will be achieved if understood and followed by all parties related to the implementation of programs in achieving the objectives set. Therefore, the willingness to accept and implement the steps in the strategic plan required a positive attitude with the goal commitment.

Goal commitment is defined as acceptance to targets set which means there is an agreement to implement (Steers \& Porter, 1974) by working in the direction of the goals set, does not work according to their own free will (Lawler \& Hackman, 1969; Weingart and Weldon 1991). Klein, Wesson, Hollenbeck, Wright, and Deshon (2001) interpret the goal commitment as a positive assessment of the goals and targets which are set and have a high concern for implementation. 
Goal commitment is also interpreted as the willingness of individuals to achieve goals (Redmon, 2011), attachment and willingness of individuals to continue to achieve the goal (Busch, Fallan, \& Pettersen, 1998), a determination to achieve the goal (DeClerq, Menzies, Diochon, \& Gasse, 2009). Some concluded that the definition of goal commitment is the willingness of employees to approve, accept, and carry out goals or targets set consistently.

By this definition, the goal commitment factors obtained are as follows.

1. Agreeing targets set means viewing positively goals and the targets set.

2. Ready to implement the targets set means caring about the achievement of goals and targets set consistently.

Factors are then defined as an indicator of goal commitment in this study. Goal commitment is the beginning of the discussion of the purpose of goal setting (Locke \& Latham, 2006). Theories of goal setting are raised and propagated by Edwin Locke in the late 1960s. Locke describes that works toward the goal are a major source of motivation for the actual goal. Individuals tend to be more persistent to increase task performance than without a clear goal setting (Locke, Shaw, Saari, \& Latham, 1981). Goals are what individuals or organizations try to achieve something (Linenburg, 2011). Harsey and Blanchard (1986) interpret the goal as the object of the act. Locke et al. (1981) refer it as action goals. Goal setting is a process of setting goals, programs, indicators, and measures in the field of employment. Goal setting is also a management idea to set targets and programs for the successful achievement of the performance.

Goal setting is often referred as target-based management system (Davis \& Newstrom, 1983). The process of implementation of effective goal setting needs to involve all members of the organization so that the goals set can be understood, agreed upon, and controlled together. Lawler and Hackman (1969) say that when the individuals participating in group goal setting procedures, productivity will increase receptively. Goal setting consists of several factors, namely goal commitment, goal specification, the difficult level of goal, and feedback. Previous researchers focus on several different factors. Locke (1991) focuses on the goal specifications and goal commitment. Mossholder (1980) pays more attention to the specification of goals. Mesch, Farh, and Podsakoff (1994) focus on goal feedbacks. Steers and Porter (1974) focus on acceptance, feedback, and employee participation in goal setting. Weingart and Weldon (1991) focus on the goal commitment. Lawler and Hackman (1969) focus on the participation and commitment. All the experts agreed that goal setting can motivate employees.

Of those all goal setting factors, Redmon (2011) stated that goal commitment is the main objective in setting goals. This statement can be understood that although the goal setting is made perfectly, man as the executor is very decisive in achieving those goals. How people who are involved in it are involved in setting those goals. Therefore, the most important thing that needs to be analyzed further is how the BRP's commitment toward goal setting. Based on it, the determination of the purpose of this research is focused on goal commitment.

According to the goal-setting theory, making goals will not take place if there is no goal commitment (Locke, Latham, \& Erez, 1988). As for goal commitment is influenced by external factors (the influence of friends, superiors, and external rewards), interactive factors (participation and competition), and internal factors (expectations and internal rewards) (Locke, 
Latham, \& Erez, 1988). These three factors become a consideration in building the model in this study.

Goal commitment determinants set by Locke et al. (1988) received empirical support from subsequent research findings such as Presslee and Jeffrey (2011) who find that external factors such as reward has a significant effect on goal commitment. The social environment consists of relationships with superiors, internal partners and external partners. Ke et al. (2008) prove that the support of superior and the work environment significantly associated with goal commitment. Even the result of a meta-analysis of Klein et al. (1999) suggests that the social environment has the highest correlation to goal commitment than other variables.

In this study, external factors which are developed as an exogenous variable of goal commitment are reward equity and communication climate that is superior supports. Interactive factors proposed in this study are variables related to the interaction of BRP to the college outsiders, called cooperative partners. An internal factor developed in this study is conscientiousness.

Goal setting at the organizational level influences on an individual or organizational performance. No matter how great is the employee, if he or she is in an organization that does not understand and follow the organizational goals, then the employee will decrease his or her performance. How the process when setting organizational goals is also associated with employee understanding and acceptance of the organizational goals. Based on this fact, the research on goal commitment is feasible to be conducted. Davis and Newstrom (1983) state that when the goal-setting is put into the operational regulation of an organization, then, the workers will understand what effort needs to be completed to achieve the results. The existence of goals and targets which are set by the organization can clearly direct the employees' work. Davis and Newstrom's research also prove that goal setting can improve employee's productivity. This condition occurs because of the positive effects of goal setting as a motivation. Individuals who work under a high level of goal performance will work harder to achieve a higher level of performance. Difficult tasks will encourage individuals to improve their performance by increasing the skills to face complex and challenging situations. Higher mastery of skills will support the individual's ability to improve his or her performance.

The hypothesis of this study is as follows. There is a positive effect between conscientiousness, communication climate, cooperative partners, and reward equity to goal commitment. The higher conscientiousness, communication climate, cooperative partners, and reward equity, the higher the BRP's goal commitment.

\section{Research Methods}

Goal commitment is a person's level of willingness to approve, accept, and carry out the goals or targets set consistently. The scale of this study consists of 5 variables, which are goal commitment as an endogenous variable; communication climate, cooperative partners, conscientiousness, and reward equity as exogenous variables. The scale of goal commitment is the development of scale created by Klein, Wesson, Hollenbeck, Wright, and Deshon (2001). The scale with self-report consists of two factors, namely employee agrees on targets and is willing to carry out the goals. Communication climate scale is a modification of the inventory of Kolb, Osland, and Rubin (1995), consists of 6 factors, namely professionalism, empathy, 
equality, openness, problem-solving oriented, descriptive. The scale cooperative opponent consists of collaboration and accommodation factors. Reward equity scale consists of internal benchmarking with itself and external with others. Conscientiousness scale consists of achievement and dependability.

The subjects of this research are 162 promotion officers of higher education which is a representation of BRP. The number of subjects is representatives from 25 universities which were taken from 130 colleges with the random cluster sampling. Analysis of research data through analysis models with Partial Least Square (PLS). The results are described in Figure 1.

\section{Results}

Initial evaluation of the measurement model is the evaluation of convergent validity and discriminant validity. Convergent validity is produced validity test of each indicator, composite reliability, and average variance extracted (AVE) (Yamin \& Kurniawan, 2011). The results show that the convergent and discriminant validities have been met so it can be said that all indicators are valid in measuring its constructs.

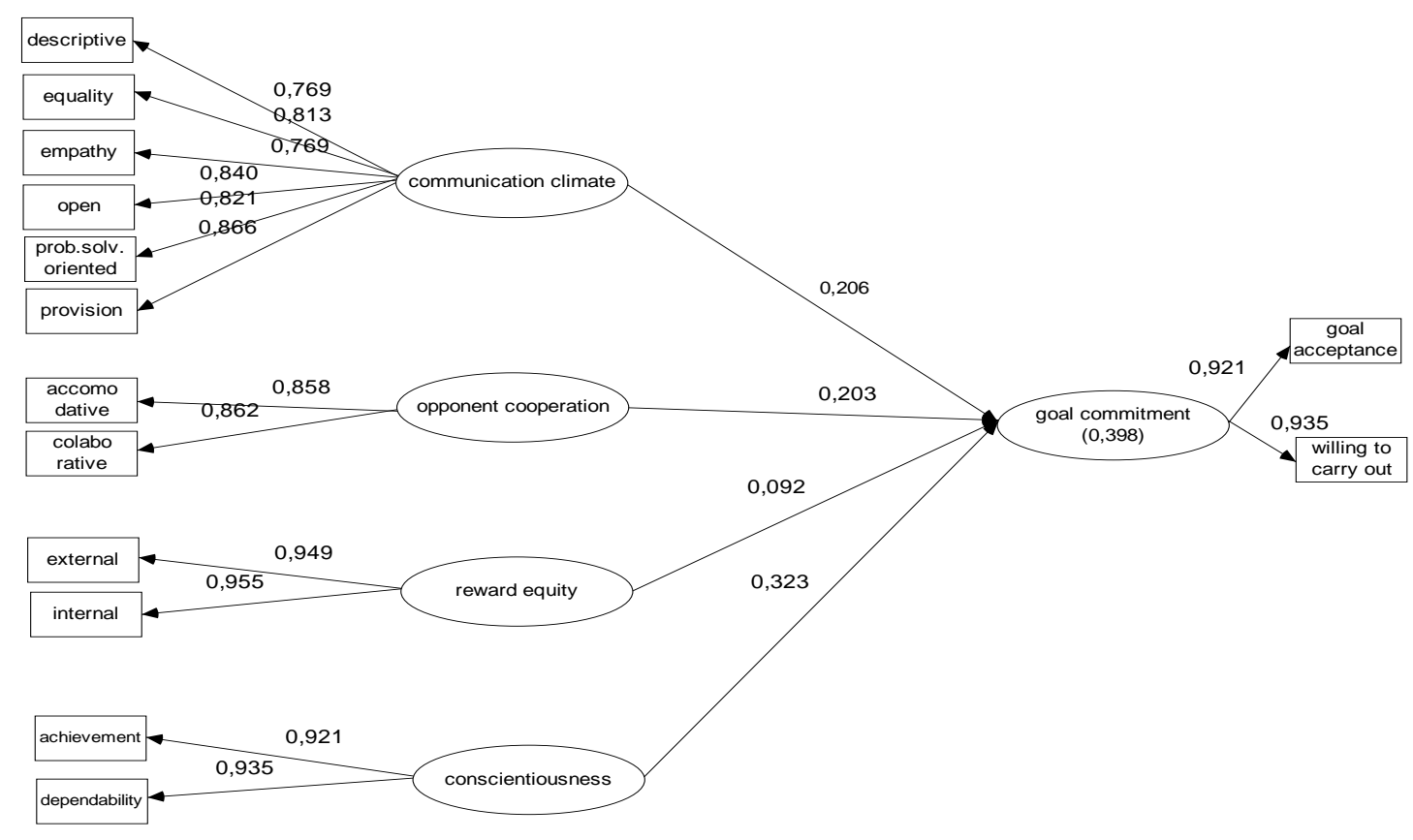

Figure 1. Analysis Results of BRP Goal Commitment Model

The result of the outer model explains that convergent and discriminant validities have been qualified. The results of inner model explained that the R-square on goal commitment variable was 0.398. Communication climate, cooperative partners, conscientiousness, and reward equity jointly affect the BRP performance. Those four predictors jointly contribute effectively to the BRP performance of $39.8 \%, 60.2 \%$ indicated that they are influenced by other variables.

The influence of communication climate to BRP's goal commitment indicated by the correlation of 0.206 that is not significant at the $5 \%$ significance level with $\mathrm{t}$-statistic value of $2.545<\mathrm{t}$-table 
(1.975). The effect of cooperative partners on the goal commitment is significant at the 0.203 significance level of $5 \%$ with t-statistic value of 2.915> t-table (1.975). Effect of reward equity against goal commitment is 0.092 that is not significant at the $5 \%$ significance level with tstatistic value of $1.534<\mathrm{t}$-table (1.975). The influence of conscientiousness on goal commitment is significant at the 0.323 significance level of $5 \%$ with $\mathrm{t}$-statistic value of $4.245>\mathrm{t}$-table (1.975). This partial picture shows that BRP's commitment to the goals set are influenced by factors conscientiousness and cooperative partners, while the communication climate and reward equity do not significantly influence the goal commitment.

This study finds that goal commitment models explain that BRP's commitment to the goals is established for the support of personal factors such as conscientiousness and the social, environmental factor outside the organization that is the level of cooperative partners. Theory of goal setting is selected as a reference for analyzing the results of this study have explained that the goal commitments are formed due to three factors, namely internal, external, and interactive. The results of this study found that the factors that influence the formation of BRP's goal commitment are internal and interactive factors. As for external factors such as reward equity and communication climate with superiors do not affect BRP's goal commitment.

Communication climate, cooperative partners, reward equity, and conscientiousness jointly affect BRP's goal commitment. The study also finds that the main factors affecting BRP's goal commitment are conscientiousness. Support from the environment that is accommodative and collaborative partners makes BRP feel comfortable to work and learn from partners outside the institution when it is committed to the goal. Goals which are positively perceived by BRP are able to strengthen his spirit to achieve optimum results so that the performance is optimal. Communication climate between BRP with a superior who is perceived positively by BRP will support BRP's commitment to accept and implement the goals set.

This model suggests that personal power is an important factor in explaining the BRP goal commitment. A conscientious whose characteristics are to have a strong spirit to reach this achievement and to be consistent with the process of attaining achievement is remarkable potential personnel for the establishment of the power of BRP goal commitment. In addition to personal factors of the social environment outside the organization that is a cooperative partner is also significant in forming goal commitment.

If it is analyzed from the theory of the formation of attitudes, attitudes are formed from the factors of the individual and from the outside of the individual. Attitudes form directly as a result of experience. They may emerge due to direct personal experience, or they may result from observation. Social roles and social norms can have a strong influence on attitudes. Social roles relate to how people are expected to behave in a particular role or context. Social norms involve society's rules for what behaviours are considered appropriate (Cherry, 2013). The attitude that comes from the observation of the partners will form a new understanding which is associated with past experiences so that through the process of cognition appears certain attitude. Description of this formation of attitudes of commitment towards the goal is the explanation of the theory of Bandura (1989) on social cognition processes. Bandura (1989) states that attitude is formed because of observational learning from interaction with the social environment. 


\section{IJBE: Integrated Journal of Business and Economics}

e-ISSN: 2549-3280

Goal commitment is a form of a working attitude. BRP's attitude in committed to the goal pursuit is motivated by the spirit of achievement and a desire to reach optimal success and learning outcomes of experience interacting with partners outside the organization. BRP is not too concerned with strengthening the external nature such as rewards and superior support, but more concerned with internal reinforcement such as achievement and pride when he is able to achieve the targets set. It illustrates that conscientiousness is an important variable for the learning process that is highly expressed in BRP's commitment to the goals set.

Based on the above description, it can be concluded as follows. Goal commitment is an attitude of work related to the personality trait conscientiousness and interactive relationships with partners outside the organization. As to the nature of personality itself has relatively settled but his behaviour can be shown to adapt to the environment. Conscientiousness is the emergence of the basic assets of BRP's goal commitment. In coincidence with BRP's job which is always related to the environment, it is important that BRP has the ability to adapt to the environment. Spirit of learning that is characteristic of conscientiousness will manifest in behaviour to find information thoroughly and attentively, and then manage the process of thinking. In the process occurs association with experience or previous information then trigger new behaviours which are appropriate to the situations. Therefore, BRP requires a thorough understanding of the environment.

Understanding of the environment makes BRP has a lot of information, so BRP is able to select and map the information in accordance with the goals set. It is done because BRP has goal commitment. Goal commitment is the most important construct in linking goals with current performance (Redmon, 2011). The goal itself is an important part of the motivation (Klein et al., 1999) . This statement is in line with Bandura (1989) who states that individuals are better able to show such behaviour if the behaviour of the model is consistent with the goals to be achieved. When the goal commitment has owned, BRP will use the environment to support their job. Partners who are willing to assist accommodatively and collaboratively become the sources of learning and benchmark in order to be more positive and innovative. Positive attitude towards the goals set is needed to deal with any environmental situation, so anything faced, BRP is still able to achieve superior performance.

This study finds that partially, reward equity and communication climate do not significantly influence the BRP's goal commitment. The differences in organizational characteristics between higher education and business organizations allow any indication that reward equity and communication climate partially do not have a significant effect on the BRP's goal commitment. Because higher educations tend voluntaristic, the reward equity does not matter for BRP in higher education. Because of consultative decision-making, then the decision is not only obtained from the employer but may consult with the various divisions. When BRP must deal with outsiders, BRP can directly discuss with the related parties in the organization without going through the superior so that the communication climate is not important for BRP's goal commitment.

This finding is interesting to be developed in the macro or organizational boundary explanation as described by Askenas, Ulrich, Prahaland, and Jick (1995). This concept has accommodated the development of today's communication. The development of communication in today's 
business organizations has evolved from face to face directly turned into communication via email, telephone, and other virtual methods. Likewise with higher colleges which have now been using technology to engage with stakeholders internally and externally, especially for the promotion of higher education. Organizations that accommodate technological developments make such organizations without boundaries, and this is what has happened today.

The concept of unbound organization developed by Askenas et al. (1995) explains the importance of the empowerment of each individual in the organization. Empowerment means making organization's goals as the responsibility of each individual instead delegated the responsibility of superiors. Empowerment as well as put the employee in the position, not as a paid employee but the business person authorized in business decisions which it is his responsibility (Askenas et al., 1995). This explanation as a critique of the weaknesses of the concept of boundary proposed by Adams (1976) that fail to accommodate changes in a fastpaced environment and across organizational boundaries penetrate even cross-country through technological advances. Based on consideration of this concept, therefore, it is very natural that reward equity and communication climate factors do not significantly influence BRP's goal commitment. As a result, it is possible that the results of this study can also be applied to the subject of the organization outside the institution, as well as profit organizations.

\section{Conclusion}

Based on the discussion of these results it can be concluded that the BRP function is to represent the organization in interacting with the environment. The interaction is required to trace and create strategic information that is useful for the progress of organizations. Information is considered strategic if it fits with the organization's goals. In addition to managing information, BRP also works in cooperation with various parties to bring the interests of the organization and carry on the agreements that have been made with parties outside the organization. Because BRP has highly strategic function within the organization, then the strength and determination of the BRP's commitment are very necessary.

The success of promotion section of higher education requires a strong personal profile, eagerly reaching accomplishments, and responsible. This personality trait is relatively settled in the individual so that when he faces turmoil in the field, BRP remains reliable. Cooperative partners are urgently needed to facilitate the search and delivery of information, collaboration, and ensuring the deal. Cooperative partners are needed to understand and align the expectations and interests of each other and be a model to learn a lot of things related to the success of BRP work.

There are several limitations of this study, such as hectic in the promotional activities of higher education, so the data retrieval process takes a little longer. BRP has very diverse pieces of work, but this study only focuses on the promotion of higher education in DI Yogyakarta so generalize the results of this study are limited to BRP promotion officers of higher education in DI Yogyakarta. 
IJBE: Integrated Journal of Business and Economics

e-ISSN: 2549-3280

\section{References}

1) Adams, J. S. (1976). The structure and dynamics of behaviour in organizational boundary roles. In M. D. Dunnette (Handbook Of Industrial And Organizational Psychology). Rand McNally College Publishing Company, Chicago.

2) Askenas, R., Ulrich, D., Prahalad, C. K., \& Jick, T. (1995). The Boundaryless Organization: Breaking the Chains of Organization Structure. San Fransisco: Jossey-Bass.

3) Bandura, A. (1989). Social cognitive theory. In R. Vasta (Ed.), Annals of child development. Vol.6. Six theories of child development (pp. 1-60). Greenwich, CT: JAI Press.

4) Barbuto, J. E., Barbuto, L., \& Rey, P. L. (2003). Predicting entrepreneurial success in the postapartheid era. Journal of Applied Psychology, 78, 715-722

5) Bento, R.F. (1998). A theoretical model of correlates of evaluation of expertise boundary role: Formulation and empirical test. Dissertation. Massachusetts Institute of Technology.

6) Berrien, F. K. (1976) A general systems approach to organizations. In Dunnette, M. D. (Handbook of industrial and organizational psychology), Rand McNally College Publishing Company, Chicago.

7) Busch, T., Fallan, L., \& Pettersen, A. (1998). Disciplinary differences in job satisfaction, selfefficacy, goal commitment, and organizational commitment, among faculty employees in Norwegian Colleges: An empirical assessment of indicators of performance. Quality in Higher Education, 4(2), 137-157.

8) Chen, Z., Zhong, J. A., \& Lam, W. (2007). Leader-member exchange and member performance: A new look at individual-level negative feedback-seeking behaviour and team-level empowerment climate. Journal of Applied Psychology, 92(1), 202-212.

9) Cherry, K. (2012). Social Learning Theory. An Overview of Bandura's Social Learning Theory. Retrieved October 27, 2012, from http://psychology.about.com/od/developmentalpsychology/a/sociallearning.htm.

10) Cherry, K. (2013). Attitudes. How Attitudes Form, Change and Shape Our Behavior. 2013 http://psychology.about.com/od/socialpsychology/a/atti-tudes.htm

11) Cooper, C. L., Rout, U., \& Faragher, (1989). Mental health, job satisfaction, and job stress among general practitioners. British Medical Journals, 298, 1405-1406.

12) Davis, K., \& Newstrom, J. W. (1989). Human behaviour at work. organizational behaviour. New York: McGraw-Hill Book Company.

13) Diamond, M., Allcorn, S., \& Stern, H. (2004). The surface of organizational boundaries: A view from psychoanalytic object relation theory. Human Relations, 57(1), 31-53.

14) Dunham, R. B., Grube, J. A., and Castaneda, M.B. (1994). Organizational commitment: The utility of an integrative definition. Journal of Applied Psychology, 79(3), 370-380.

15) Erez, A., \& Judge, T. A. (2001). Relationship of core self-evaluations to goal setting, motivation, and performance. Journal of Applied Psychology, 86(6), 1270-1279.

16) Erez, M. (1977). Feedback: A necessary condition for the goal setting-performance relationship. Journal of Applied Psychology, 62(5), 624-627.

17) Fisman, R., \& Khanna, T. (1999). Is trust a historical residue? Information flows and trust levels. Journal of Economic Behavior and Organization, 38(1), 79-92.

18) Fried, Y., \& Ferris, G. R. (1987). The validity of the job characteristics model: A review and metaanalysis. Personnel Psychology, 40(2), 287-322. doi: 10.1111/j.1744-6570.1987.tb00605.x

19) Gilboa, S., Shirom, A., Fried, Y., \& Cooper, C. (2008). A meta-analysis of work demand stressors and job performance: Examining main and moderating effects. Personnel Psychology, 61(2), 227271.

20) Hersey, P. \& Blanchard, K. H. (1986). Manajemen perilaku organisasi (edisi ke empat). Terjemahan oleh Agus Dharma. Jakarta: Penerbit Erlangga.

21) Jadhav, A. (2007). Effect of locus of control, self-efficacy, and conscientiousness on goal commitment and performance. Northern Kentucky University. Retrieved Februari 12, 2013 from 
IJBE: Integrated Journal of Business and Economics

e-ISSN: 2549-3280

http://books.google.co.id/

books

/about/

Effect_of_Locus_of_Control_Self_efficacy.html?id=84qkuAAACAAJ\&redir_esc=y

22) Kamdar, D. \& Dyne, L. V. (2007). The joint effects of personality and workplace social exchange relationship in predicting task performance and citizenship performance. Journal of Applied Psychology, 92(5), 1286-1298.

23) Klein, H. J., Wesson, M. J., Hollenbeck, J. R., Wright, P. M., \& DeShon, R. P. (2001). The assessment of goal commitment: A measurement model meta-analysis. Organizational Behavior and Human Decision Process, 85, 32-55.

24) Klein, H. J., Alge, B. J., Wesson, M. J., \& Hollenbeck, J. R. (1999). Goal commitment and the goalsetting process: Conceptual clarification and empirical synthesis. Journal of Applied Psychology, 84(6), 885-896.

25) Kolb, D. A., Osland, J. S., \& Rubin, I. M. (1995). Organizational behavior. New Jersey: PrenticeHall International, Inc.

26) Latham, G. P., \& Locke, E. A. (1983) Goal setting - A motivational technique that works. In Steers, R. M., \& Porter, L. W. (Motivation and work behavior). Singapore: McGraw-Hill Book Company

27) Lawler, E. E., \& Hackman, J. R. (1969). Impact of employee participation in the development of pay incentive plans: A field experiment. Journal of Applied Psychology, 53, 457-471.

28) Linenburg, F. C. (2011). Goal-setting theory of motivation. International Journal of Management, Business, and Administration, 15(1), 1-7.

29) Locke, E. A. (1991). Problems with goal-setting research in sports and their solution. Journal of Sport and Exercise Psychology, 13, 311-316.

30) Locke, E. A., Shaw, K. N., Saari, L. M., \& Latham, G. P. (1981). Goal setting and task performance: 1961-1980. Psychological Bulletin, 90, 125-152.

31) Locke, E.A., \& Latham, G.P. (2006). New directions in goal-setting theory. Current Directions in Psychological Science, 15 (5), 265-268. doi: 10.1111/j.1467-8721.2006.00449.x

32) Locke, E. A., \& Latham, G. P., \& Erez, M. (1988). The determinants of goal commitment. The Academy of Management Review, 13 (1), 23-29.

33) Mehra, A., \& Schenkel, M.T. (2005). Self-monitoring, boundary spanning, and role conflict in the workplace. Journal of Academy of Marketing Science, 14, 36-46.

34) Mesch, D. J., Farh, J. L., \& Podsakoff, P. M. (1991). Effects of feedback sign on group goal setting, strategies, and performance. Group and Organization Management, 19, 309-333.

35) Mossholder, K. W. (1980). Effects of externally mediated goal setting on intrinsic motivation: A laboratory experiment. Journal of Applied psychology, 65(2), 202-210.

36) O'kelly (2007). Setting effective boundaries volunteer. Canadian Journal of Volunteer Resources Management, 15, 13-16.

37) Perry, J. L., \& Angle, H. L. (1979). The politics of organizational boundary roles in collective bargaining'. The Academy of Management Review, 4, 467-495.

38) Pruitt, D. A., \& Schwartz, R. A. (1999). Student affair work as boundary spanning: An exploratory study. College Student Affairs Journal, 19(1), 62-87.

39) Redmon, B. F. (2011). Work Attitudes and Job Motivation.Retrieved June 20, 2022 from http://wikispaces.psu.edu /display/PSYCH484/6+Goal+Setting.

40) Schredl, M., Bocklage, A., Engelhardt, J., \& Mingebach, T. (2008). Psychological boundaries, dream recall, and nightmare frequency: A new Boundary Personality Questionnaire (BPQ). International Journal of Dream Research, 1(2), 12-19.

41) Spekman, R. E. (1979). Influence and information: An exploratory investigation of the boundary role person's basis of power. Academic of Management Journal, 22(1), 104-117

42) Steers, R. M., \& Porter, L. W. (1974). The role of task-goal attributes in employee performance. Psychological Bulletin, 81(7), 434-452.

43) Weingart, L. R. \& Weldon, E. (1991). Processes that mediate the relationship between a group goal and group member performance. Human Performance, 4(1), 33, 54. 
IJBE: Integrated Journal of Business and Economics e-ISSN: 2549-3280

44) Winslow, G. R., \& Winslow, B. J. W. (2007). Ethical boundaries of spiritual care. The Medical Journal of Australia (MJA), 186, 63-66.

45) Wright, P. M. (1992). An examination of the relationships among monetary incentives, goal level, goal commitment, and performance. Journal of Management, 18(4), 677-693.

46) Yamin, S., \& Kurniawan, H. (2011). Partial least square path modeling. Jakarta: Penerbit Salemba Infotek. 